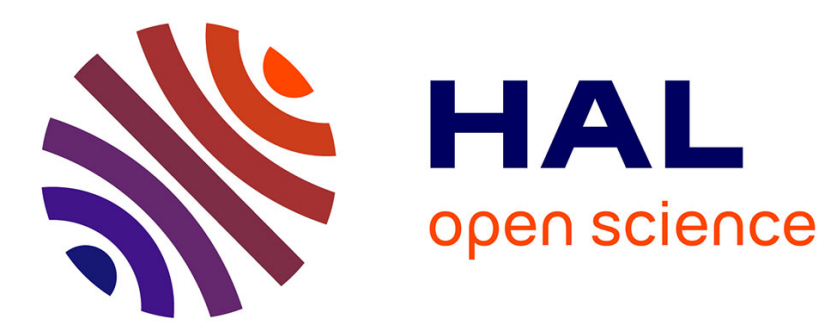

\title{
Experiencing uncertain HIV treatment delivery in a transitional setting: qualitative study.
}

Sarah Bernays, Tim Rhodes

\section{To cite this version:}

Sarah Bernays, Tim Rhodes. Experiencing uncertain HIV treatment delivery in a transitional setting: qualitative study.. AIDS Care, 2009, 21 (03), pp.315-321. 10.1080/09540120802183495 . hal00513463

\section{HAL Id: hal-00513463 \\ https://hal.science/hal-00513463}

Submitted on 1 Sep 2010

HAL is a multi-disciplinary open access archive for the deposit and dissemination of scientific research documents, whether they are published or not. The documents may come from teaching and research institutions in France or abroad, or from public or private research centers.
L'archive ouverte pluridisciplinaire HAL, est destinée au dépôt et à la diffusion de documents scientifiques de niveau recherche, publiés ou non, émanant des établissements d'enseignement et de recherche français ou étrangers, des laboratoires publics ou privés. 

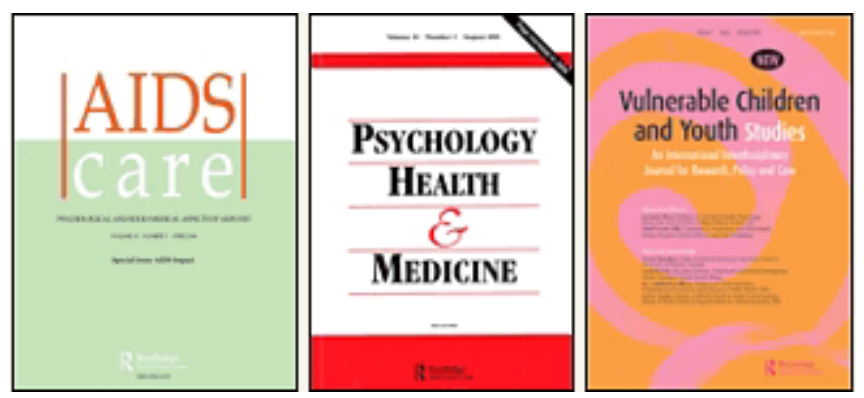

\section{Experiencing uncertain HIV treatment delivery in a transitional setting: qualitative study.}

\begin{tabular}{|r|l|}
\hline Journal: & $\begin{array}{l}\text { AIDS Care - Psychology, Health \& Medicine - Vulnerable Children } \\
\text { and Youth Studies }\end{array}$ \\
\hline Manuscript ID: & AC-2007-11-0599.R1 \\
\hline Journal Selection: & AIDS Care \\
\hline Keywords: & HIV treatment, adherence, rationing, qualitative, transitional \\
\hline
\end{tabular}

\section{s scholarONE" \\ Manuscript Central}




\title{
Experiencing uncertain HIV treatment delivery in a transitional setting: Qualitative study
}

\begin{abstract}
$\underline{\text { Abstract }}$
Background Advances in HIV treatment availability mean that the promise of highly active antiretroviral treatment (HAART) to turn HIV into a manageable chronic illness is becoming a reality for millions. However the mutability of the virus means that treatment adherence demands are high, and the supply of these life-saving treatments needs to be constant. The onus is generally placed on the individual to adhere, and there is little focus in research or policy on the state's adherence to delivering treatment consistently.
\end{abstract}

Methods We undertook in-depth qualitative interviews to explore the narratives of HIV treatment experience among 41 people living with HIV infection (PLHIV) and 18 HIV treatment service providers in Serbia and Montenegro, a transitional setting in which state-delivered and funded HIV treatment is inconsistently available. Data were analysed inductively and thematically.

Findings Treatment shortages were common so the delivery of appropriate HIV treatment was not continuous. Access to reliable treatment and supply forecast information was weak and uneven. The insecure treatment situation fostered significant anxiety amongst PLHIV.

Interpretation In the absence of reliable and sustained treatment access, information and support, PLHIV absorb the anxieties of system failures. This uncertainty led to an individuation of 'treatment'. PLHIV adopted rationing strategies to mediate their anxiety, energy and hope. This predominately resulted in varying forms of disengagement and neglect for social change. It is likely that this has significant negative implications for the promotion of HIV treatment advocacy and anti-stigma efforts.

Keywords: HIV treatment; adherence; rationing; uncertainty; Qualitative; Serbia; Montenegro 


\section{Introduction}

Most qualitative research exploring narratives of HIV treatment experience has centred on settings in which HIV treatment access is relatively secure (Davies, 1997; Ezzy, 2000). Such research has focused primarily on the renegotiation of personal and health identities in light of treatment potential and success (Brashers et al., 1999; Carricaburu \& Pierret, 1995; Selwyn \& Arnold, 1998; Siegal \& Lekas, 2002). More recently, qualitative research has explored the influence of 'treatment optimism' on risk behaviour, (Elford, Bolding, \& Sherr, 2002) and how HIV positive individuals engage with medical knowledge relating to their HIV treatment (Brashers et al., 2003; Davis, 2007; Davis, Frankis, \& Flowers, 2006; Kielmann et al., 2005; Rosengarten, Miris, Flowers, Davis, \& Hart, 2004; Tiamson, 2002).

Clinical uncertainty has been a dominant feature of the HIV treatment experience (Brashers et al., 2003; Chidwick \& Borrill, 1996; Crossley, 1998; Davis, Frankis, \& Flowers, 2006; Kielmann et al., 2005; Weitz, 1989). In resource-rich settings, this uncertainty has been prescribed by technological advances in treatment and underpinned by individual adaptation to medical innovation (Davis, Frankis, \& Flowers, 2006). However the experience of HIV treatment in secure delivery settings is unlikely to be directly translatable to settings in which consistent access to treatment, due to social and economic constraints, is itself uncertain.

The unprecedented challenge of scaling-up HIV treatment in resource-constrained settings has meant that research has predominately focused on demonstrating the viability of HIV treatment in such settings (Curran et al., 2005; Farmer, Léandre et al., 2001; Thimothy, Kumar, \& Irudaya Rajan, 2006), monitoring treatment delivery and targets, and supporting individuals' treatment adherence (Chesney, 2003). However, given the life-long nature of HIV treatment once initiated, research is needed to understand how HIV treatment decisions are managed in the context of competing constrained resources. Qualitative evidence emerging from South Africa demonstrates that HIV treatment is 'juggled' alongside other competing needs, with individuals strategically rationing treatment to maintain financial survival, sometimes by staying 'ill enough' to retain a disability grant (Leclerc-Madlala, 2006).

Despite intensive efforts to strengthen treatment delivery infrastructures, the fragility of some health systems have been exposed by the staggering scale of HIV treatment scale-up. This has been compounded by donor dependency and substantial logistical obstacles. Treatment security is an ongoing concern in many regions. In Uganda, experience of shortages in state funded HIV 
treatment have led senior national HAART procurement managers to call for individuals to save money to cover their own purchases of rationed drug supplies (Kasanga \& Bainemigisha, 2006). There are frequent reports in resource-constrained settings of treatment shortfalls resulting from delivery blockages, financial problems and human error.(IRIN, 2006a, , 2006b, , 2007; Kyokuhaire, 2006).

There is scant research that focuses on the social impact of fragile treatment delivery and a need for a social science of scale up The aim of this qualitative study was to explore what impact fragile delivery of HIV treatment has upon the experience of living with HIV in Serbia and Montenegro. 


\section{Methods.}

Between October 2005 and November 2006, we undertook a qualitative study among 41 PLHIV and 18 HIV treatment providers in Serbia and Montenegro. The study comprised in-depth qualitative interviews among a purposively selected sub-sample of participants.

\section{Setting}

South Eastern Europe, including Serbia and Montenegro, has recently experienced large scale social and economic disruption, including political transitions contextualised by conflict and uncertainty, resulting in population displacement and increased health vulnerability. The HIV epidemic in South Eastern Europe is small in comparison to Eastern Europe but there are parallels in the risk environment (Rhodes \& Simic, 2005). In 2006, there were 1,250 PLHIV registered in Serbia and Montenegro. 600 patients received care at the one HIV clinic in the country, 520 of whom received HAART (Simic, 2006). Treatment has been state funded since 2002. HAART was prescribed one month at a time from this clinic and administered by the National Central Pharmacy. Monitoring tests for CD4 and PCR were intermittently available. The frequency of testing varied amongst patients between 3 times/ year to not at all. We describe constraints relating to the treatment system elsewhere (Bernays et al 2007).

\section{Sampling and recruitment}

Recruitment was via contacts with local NGOs (21) and snowballing within PLHIV networks (14). Through these avenues 40 PLHIV were approached, with 5 refusing to participate. In order to reach those outside of these networks we also advertised for participants at the national HIV clinic (6). Recruitment and data collection were undertaken in three waves to enable provisional coding to inform the focus of ongoing recruitment and data collection.

Over half of the HIV positive participants were living in Belgrade at the time of the study, where approximately $70 \%$ of the HIV population of Serbia and Montenegro reside (Simic, 2006). Participants from outside Belgrade were recruited from areas in north and southern Serbia (Vojvodina, $n=8$; Nis, $n=4$ ), and from Montenegro $(n=5)$. The age of participants ranged from 2278 years, with the median age being 35 years old.

We also recruited 18 HIV treatment service providers. These comprised key national representatives of the treatment supply chain, as well as specialist HIV medical staff and NGO personnel. 


\section{Data collection}

Data collection was via in-depth interviews, most of which (30/41) took place in participants' homes. Interviews were facilitated by a topic guide, and designed to explore participants' narratives. Key areas of discussion included: HIV diagnosis; treatment history; experience of HIV treatment and health care; attitudes towards and experience of disclosing status; and HIV community activity. Interviews were tape recorded and undertaken in Serbian (15), via translation (21) and in English when requested by the participant (5). Additional core structured questions were asked in relation to sample characteristics. All participants were reimbursed 7 Euros for their participation.

\section{Analysis}

All interviews were transcribed verbatim and translated for coding and analysis. We assessed the quality of translation by transcribing and translating both the participants' and translators' responses in the first 10 interviews conducted via simultaneous translation, and very little divergence in the articulation of responses was found.

The analysis of data was thematically driven. Key emerging themes included; uncertainty, diminished trust, rationing and individualisation. Initial first level coding was undertaken by the authors and second level coding largely sought to break down first level-coding into smaller units. Analytical bias was addressed through the transparent organisation and categorisation of data using word processing software and justifying themes with reference to negative cases (Silverman, 2000). In order to protect participants' anonymity, interviewees are identified by a number and whether they are HIV positive (PLHIV) or a service provider (SP).

\section{Ethics}

The study had ethical approval from the Charing Cross Hospital Ethics Committee and in the absence of an ethics committee approval was given by the Ministries of Health, and Republican AIDS Commissions, of Serbia and Montenegro. All interviews were conducted with informed consent. 


\section{$\underline{\text { Results }}$}

\section{Fragile access to continuous HIV treatment}

There was a consensus in participant accounts that HIV treatment medications and monitoring tests were not continuously available, and that this was a consequence of supply shortages. HIV treatment providers employed two strategies to manage treatment shortages. One was to stop treatment until the appropriate medication became available again. The alternative strategy was to change the regimen of treatment. The sporadic availability of monitoring tests made these decisions even more precarious:

'The treatments are just each month what they have in the pharmacy... without any medical check you know, without any check of blood or some support so that you can see those tests say, 'OK you can take that'. It is a very big problem. Now my treatment is available at the pharmacy but I don't know for how long.' (PLHIV 33)

The unpredictability of supplies made planning patients' treatment very difficult: "We can't have any plan, because we don't know when supplies will fail" (SP 9). In this environment of fluctuating supplies, the distribution of treatment was uneven: "Some people can get medicines and some can't" (PLHIV 33). Treatment was therefore experienced by PLHIV as individualising and intensely uncertain: "It is like waiting in a line and you really don't know if your turn is going to come" (PLHIV 28). This anxiety was felt amongst all participants and there was no gender specific variation.

In response to this, PLHIV also themselves engaged in a rationing process. Whilst in some cases such constrained resources were a cause of "tension between people", in other cases it facilitated informal friendship networks as people exchanged treatment amongst themselves.

\section{HIV treatment uncertainty}

The perceived fragility of the HIV treatment system caused almost unanimous concern amongst PLHIV. Participants' accounts emphasised the perennial "fear" and "uncertainty" that they experienced in relation to the continuity and sustainability of supplies:

'Everybody's in trouble because you have constantly the worry about what's happening today and after today'. (PLHIV 20) 
'It's really terrible. I'm much more confident when I am on treatment. Like this [without treatment] as soon as I notice something hurts a little I get scared, but no one asks me and there are no medicines. I live from one day to another.' (PLHIV 42)

Despite the theme of anxiety linked to HIV treatment uncertainty being unanimous across the accounts of PLHIV, there was disagreement in the accounts of service providers as to the gravity of the treatment situation. Some service providers felt that the fragile treatment situation seriously undermined the quality of life and the capacity PLHIV had to manage HIV as a manageable chronic illness: "I think it has terrible impact. They were afraid all the time. Some of them are in a really bad condition" (SP 3). Crucially this was said to have negative influence on participants' trust in the effectiveness of HAART: "They don't believe in this therapy here after that [treatment shortages]" (SP 4).

Others, generally those working within or representing the treatment system, acknowledged the problem but contextualised it alongside a spectrum of problems facing resource-stretched Serbia and Montenegro. These latter accounts emphasised that treatment expectations should be adjusted from an international ideal to a locally realistic level:

"It's not the correct way but... we can not live like in France, and we must deal with it, doctors also must deal with it...The patients are happy to have treatment, any treatment.' (SP 2)

\section{Rationing treatment information}

We found that the uncertainty recounted by participants was exacerbated by a perceived lack of authority and trust in relation to the information available about HIV treatment. Participants described available information as being "unreliable" or "based on gossip":

"The talk with people and in the media is always these terrifying headlines like: There won't be any medicines; or There won't be enough money for HIV treatment. I feel this influences the psychological state of people, they fall into depression. They feel they have no future." (PLHIV 34)

In a context of frequent and alarmist rumours concerning HIV treatment shortages and low treatment literacy, a lack of faith in the authority of information available fostered an atmosphere 
of confusion and fear for many PLHIV about how best to manage HIV treatment opportunities and the consequences of interrupted drug courses. In the absence of reliable information sources and with reportedly low use of the internet, most relied upon the national HIV clinic. Yet due to the high workload of the three HIV specialists, opportunities to discuss treatment or supplies with patients were rare. Additionally, information about the consequences of treatment interruption and unmonitored switching was deliberately rationed by service providers in order to mediate anxiety:

"Of course it's not good, we know that, but it's not necessary to... make them fear." (SP 2)

Access to information about HIV treatment availability appeared unevenly distributed among participants. Information relating to treatment availability is rationed not only by the system, but also between patients, with information about treatment frequently traded like a currency:

"If you are lucky someone remembers to call you and tell you [monitoring tests are available] and then you have to run, run to the clinic!....It is hard when someone is in a better position just because that person has information and so that person can access some service." (PLHIV 33)

\section{Disengagement from the system}

Accessing treatment was perceived as the individuals' responsibility. Participants described a lack of accountability amongst senior level service providers to manage treatment supply shortages. We found that this undermined participants' trust in the system and its ability to prevent or react to further shortages. Many interpreted this silence to reflect and further reinforce stigma associated with HIV:

“You don't know who's responsible and then you don't know who to complain to when there aren't any medicines.....I think that the whole thing is connected with stigma. It's like keep quiet: you've got whatever you get." (PLHIV 28)

The level of distrust in the sustainable provision of supplies meant that even during extended periods of stability the majority of PLHIV continued to perceive treatment access to be insecure and remained anxious about the sustainability of supplies. Subject to the state's perceived 
inability to provide them with appropriate treatment without interruption, many characterised their situations as being liminal, fluctuating between a manageable chronic illness and a terminal illness.

"Many of my friends were also on a treatment interruption because we did not have medicines. We started to be desperate at that time because somebody who has been on treatment for a few years, suddenly they found hope again and when you don't have treatment everything is lost." (PLHIV 1)

\section{The individualisation of treatment}

We identified three principal strategies employed by participants to manage their HIV treatment uncertainty. The first strategy was to invest significant time and energy fostering networks and resources, such as spending a great deal of time at the HIV clinic, to ensure optimum access to information and treatment. This acted as a form of social capital to generate security: "It depends how much someone is pushing. There are the patients who have tests regularly" (PLHIV 34). The second was to continue with treatment but ration contact with other PLHIV and HIV related service provision in order to mediate the risk of anxiety by "avoiding other PLHIV" and alarming rumours: "Other than what I hear from the doctors I won't allow anything else [information] to come near me" (PLHIV 27). The third strategy adopted by a few participants was to stop taking treatment or choose not to start because they saw the situation as too precarious and "more risk than things to gain" (SP 3).

The individualisation of treatment and its uncertainties interplays with weak social and community support for PLHIV. The involvement of PLHIV in NGOs, self support groups and HIV community action is relatively weak in Serbia and Montenegro (Bernays, Rhodes, \& Prodanovic, 2007). Service provider accounts attributed this to PLHIV's concerns around the disclosure risks of being involved. Whilst this was a factor, PLHIV themselves placed far greater emphasise on needing to prioritise their time and energy for 'chasing treatment'. As one person active in community action explained:

"People won't come! And now I know why: it's not just the thing if someone will see them or not, if they will give their name, but the thing is that they can hardly survive, have the therapy each month! If we had it for six months, and took it monthly, if I could go each month and say: "Hello, I'm here to get my medicines."... but like this when 
you're thinking every month about it, you can hardly think of self-help groups, some volunteer work, and paid work." (PLHIV 40)

Community support organisations were generally perceived to have a low life expectancy: "Just like the medicines they are a blink of hope" (PLHIV 1). The lack of trust in their longevity further undermined participants' motivation to risk disclosure by participating in community action.

\section{$\underline{\text { Discussion }}$}

\section{The individuation of treatment}

We found that uncertain or inconsistent treatment access contributed to patient anxiety, which in an absence of reliable information about treatment or trust in the treatment system, fostered the 'individualisation' of treatment. Individuals absorbed the anxieties resulting from system weaknesses. The unsystematic distribution of treatment resources meant that access, to a certain extent, depended on individuals' efforts to foster relations with medical staff and their peer networks.

Various forms of 'rationing' emerged as a strategy to manage treatment uncertainty as well as access to treatment. We identified three forms of rationing: information; expectation; time/energy. Information about treatment was rationed by service providers to PLHIV, and among PLHIV, where information about treatment was traded like a currency. Expectations, as well as hope, were rationed on the basis of the experience of treatment uncertainty and system failure becoming habituated in a setting of transition and resource constraint. The time and energy of PLHIV was largely absorbed by managing HIV treatment access and uncertainty, and was thus rationed elsewhere, including in relation to HIV community participation.

\section{The implications of inconsistent treatment}

Current evidence, underpinned by findings which prompted the premature cessation of the SMART study (Crabb, 2006), suggests a need for continuous adherence to HIV treatment to minimise treatment failure and maintain long term health (Pai, Lawrence, Reingold, \& Tulsky, 2006). Strategies of unmonitored stopping and treatment switching in order to temporarily respond to supply gaps therefore raise serious concerns (Martin \& Sim, 2005) . 
In addition, this study emphasises the social impact of inconsistent treatment. We found that the perceived failure of the treatment system to deliver can foster a relinquishing of trust in treatment expertise, which in turn may limit expectation and discourage motivation and adherence. Treatment needs to be perceived as effective and sustainable if it is to contribute to tackling stigma (Farmer, Leandre et al., 2001). For example, improved access to treatment in resource constrained settings has helped encourage HIV community participation (Lange, Perriens, Kuritzkes, \& Zewdie, 2004) and HIV testing (WHO, 2003). Our study suggests that the motivation PLHIV have to challenge stigma through open disclosure and community action is weakened because they are consumed with the physical and psychological effort of surviving the liminal state of fragile treatment opportunity.

In order to better capture the fluidity of the treatment situation we are conducting a follow-up study with multiple interviews to capture the impact over time. Data from a follow-up study indicate that the situation is improving, due to the implementation of longer term procurement and financing plans, but availability issues still recur and anxieties persist.

\section{Conclusion}

HIV treatment scale up creates a heavy burden on relatively weak health care infrastructures (Kim \& Farmer, 2006; Knapp, 2004). This qualitative study is one of few (Bayer \& Oppenheimer, 2007) to explore the lived experience of uncertain HIV treatment in a context of resource constraint . It shows that fragile access to HIV treatment, and the resulting uneven nature of the treatment experience, can have significant influence on participants' perceptions of their health and quality of life.

The generalisability of our findings are grounded in the specific sample and setting of our study. However they may have relevance to other settings in which HIV treatment access or delivery is inconsistent and where patient or provider rationing in relation to treatment occurs. Our findings show that insecure treatment delivery can individualise the struggle of PLHIV and undermine community participation efforts to advocate for improved treatment and tackle stigma. This is likely to have an impact on HIV prevention efforts as well as the lives of PLHIV. 


\section{Acknowledgements}

Source of funding for study: Department for International Development, UK.

\section{Conflicts of interest}

There are no conflicts of interest. 


\section{References}

Bayer, R., \& Oppenheimer, G. (2007). Scale Ups, Scaracity and Selections: The Experience of Doctors in South Africa. AIDS, 21 (Suppl 5), S43-S47.

Bernays, S., Rhodes, T., \& Prodanovic, A. (2007). HIV Treatment Access, Delivery and Uncertainty: A Qualitative Study in Serbia and in Montenegro Belgrade: United Nations Development Program.

Brashers, D. E., Neidig, J. L., Cardillo, L. W., Dobbs, K. W., Russell, J. A., \& Haas, S. M. (1999). 'In an important way, I did die': uncertainty and revival in persons living with HIV and AIDS. . AIDS Care 1999(11).

Brashers, D. E., Neidig, J. L., Russell, J. A., Cardillo, L. W., Haas, S. M., Dobbs, L. K., et al. (2003). The medical, personal and social causes of uncertainty in HIV illness. Issues in Mental Health Nursing, 24, 497-522.

Carricaburu, D., \& Pierret, J. (1995). From biographical disruption to biographical reinforcement: the case of HIV positive men. Sociology of Health and Illness, 17, 65-88.

Chesney, M. (2003). Adherence to HAART regimens. AIDS Patient Care STDS, 17, 160177.

Chidwick, A., \& Borrill, J. (1996). Dealing with a life-threatening diagnosis: the experience of people with the human immunodeficiency virus. AIDS, 8, 271-284.

Crabb, C. (2006). SMART researchers plan follow through. AIDS, 20, N5-N6.

Crossley, M. L. (1998). 'Sick role' or 'Empowerment'? The ambiguities of life with a HIV positive diagnosis. Social Science and Medicine, 20, 507-531.

Curran, J., Debas, H., Arya, M., Kelley, P., Knobler, S., \& Pray, L. (2005). Scaling up treatment for the Global AIDS Pandemic: Challenges and Opportunities. Committee on examining the probable consequences of Alternative patterns of widespread antiretroviral drug use in resource constrained settings. Washington D.C.: National Academic Press.

Davies, M. (1997). Shattered assumptions: Time and the experience of long-term HIV positivity. Social Science and Medicine, 44, 561-571.

Davis, M. (2007). Identity, expertise and HIV risk in a case study of reflexivity and medical technologies. Sociology, 41(6), 1003-1019.

Davis, M., Frankis, J., \& Flowers, P. (2006). Uncertainty and 'technological horizon' in qualitative interviews about HIV treatment. Health, 10, 323-344.

Elford, J., Bolding, G., \& Sherr, L. (2002). High-risk sexual behaviour increases among London gay men between 1998 and 2001:what is the role of HIV optimism? . AIDS, 16, 1537-1544.

Ezzy, D. (2000). Illness narratives: time, hope and HIV. Social Science and Medicine, 50, 605-617.

Farmer, P., Leandre, F., Mukherjee, J., Gupta, R., Tarter, L., \& Yong Kim, J. (2001). Community-based treatment of advanced HIV disease: introducing DOT-HAART (directly observed therapy with highly active antiretroviral therapy). . Bulletin of WHO, 79, 1145-1151.

Farmer, P., Léandre, F., Mukherjee, J., Sidonise, C., M., Nevil, P., Smith-Fawzi, M., et al. (2001). Community-based approaches to HIV treatment in resource-poor settings The Lancet, 358(9279), 404-409.

IRIN. (2006a, 15th November 2006. ). Togo: end of grant causes concern. IRIN. 
IRIN. (2006b, 13th February 2006). Zambia: ARV rollout-quality not quantity? . IRIN.

IRIN. (2007, 2 March 2007). Burundi: Outrage and concern over national ARV strategies. IRIN.

Kasanga, K., \& Bainemigisha, H. (2006, Sept 19 2006). Doctor urges on ARV scarcity New Vision.

Kielmann, K., Deshmukh, D., Deshpande, S., Datye, V., Porter, J., \& Rangan, S. (2005). Managing uncertainty around HIV/AIDS in an urban setting: Private medical providers and their patients in Pune, India. Social Science and Medicine, 61, 1540-1550.

Kim, J. Y., \& Farmer, P. (2006). AIDS in 2006- Moving toward One World, One Hope? New England Journal of Medicine, 355(7), 645-647.

Knapp, C. (2004). Antiretrovirals give new hope and new life to South Africans. Lancet, $363,1710$.

Kyokuhaire, G. (2006, 25th July 2006). ARVs will kill more Ugandans. New Vision.

Lange, J., Perriens, J., Kuritzkes, D., \& Zewdie, D. (2004). What policymakers should know about drug resistance and adherence in the context of scaling-up treatment of HIV infection. . AIDS, $18 \mathrm{S3}$, s69-s74.

Leclerc-Madlala, S. (2006). 'We will eat when I get the grant': negotiating AIDS, poverty and antiretroviral treatment in South Africa African Journal of AIDS Research, 5(3), 249-256.

Martin, D. J., \& Sim, J. (2005). Laboratory Requirements for Scaling Up HIV Treatment. Paper presented at the 12th Conference on Retroviruses and Opportunistic Infections, Boston, Boston.

Pai, N. P., Lawrence, J., Reingold, A. L., \& Tulsky, J. P. (2006). Structured Treatment Interruption (STI) in chronic unsuppressed HIV infection in adults. Cochrane Database Systematic Review 3, CD006148.

Rhodes, T., \& Simic, M. (2005). Transition and the HIV risk environment British Medical Journal, 331, 220-223.

Rosengarten, M., Miris, J., Flowers, P., Davis, M., \& Hart, G. (2004). After the euphoria: HIV medical technologies from the perspective of their prescribers Sociology of Health and Illness, 26, 575-596.

Selwyn, P., \& Arnold, R. (1998). From Fate to Tragedy: The changing meaning of Life, Death and AIDS. . The Annals of Internal Medicine, 129, 899-902.

Siegal, K., \& Lekas, H. (2002). AIDS as a chronic illness: psychosocial implications. . AIDS, 16, S69-S76.

Silverman, D. (2000). Doing qualitative research: A practical handbook. London: Sage.

Simic, D. (2006). The Epidemiological Situation of HIV/AIDS in Serbia in the period 1984-30th June 2006 Belgrade: Centre for Prevention and Control of Infectious Diseases, Institute of Public Health of Serbia.

Thimothy, R., Kumar, A., \& Irudaya Rajan, S. (2006). Viability of providing HIV/ AIDS Care in Public Sector: A case study. . Journal of Health Management, 8(1), 65-78.

Tiamson, M. (2002). Challenges in the management of the HIV patient in the third decade of AIDS. Psychiatric Quarterly 73, 51-58.

Weitz, R. (1989). Uncertainty and the lives of persons with AIDS. Journal of Social Health and Behaviour, 30, 270-281. 
WHO. (2003). Médicins sans Frontières South Africa, Department of Public Health at University of Cape Town, Provincial Administration of Western Cape, South Africa. Antiretroviral therapy in primary health care: experience of the Khayelitsha Programme in South Africa. : World Health Organisation. 